\title{
Venous thrombosis in users of non-oral hormonal contraception: follow-up study, Denmark 2001-10
}

\author{
(C) $(1) \Theta$ OPEN ACCESS
}

\author{
Øjvind Lidegaard professor ${ }^{1}$, Lars Hougaard Nielsen statistician ${ }^{1}$, Charlotte Wessel Skovlund data \\ manager $^{1}$, Ellen Løkkegaard senior registrar ${ }^{2}$
}

${ }^{1}$ Gynaecological Clinic 4232, Blegdamsvej 9, DK-2100 Copehagen Ø, Juliane Marie Centre, Rigshospitalet, University of Copenhagen, Denmark; ${ }^{2}$ Department of Obstetrics and Gynaecology, Hillerød Hospital, University of Copenhagen, Denmark

\begin{abstract}
Objective To assess the risk of venous thrombosis in current users of non-oral hormonal contraception.

Design Historical national registry based cohort study.

Setting Four national registries in Denmark.

Participants All Danish non-pregnant women aged 15-49 ( $n=1626$ 158), free of previous thrombotic disease or cancer, were followed from 2001 to 2010.

Main outcome measures Incidence rate of venous thrombosis in users of transdermal, vaginal, intrauterine, or subcutaneous hormonal contraception, relative risk of venous thrombosis compared with non-users, and rate ratios of venous thrombosis in current users of non-oral products compared with the standard reference oral contraceptive with levonorgestrel and 30-40 $\mu \mathrm{g}$ oestrogen. Diagnoses were confirmed by at least four weeks of anticoagulation therapy after the diagnosis.
\end{abstract}

Results Within 9429128 woman years of observation, 5287 first ever venous thrombosis events were recorded, of which 3434 were confirmed. In non-users of hormonal contraception the incidence rate of confirmed events was 2.1 per 10000 woman years. Compared with non-users of hormonal contraception, and after adjustment for age, calendar year, and education, the relative risk of confirmed venous thrombosis in users of transdermal combined contraceptive patches was 7.9 (95\% confidence interval 3.5 to 17.7 ) and of the vaginal ring was 6.5 (4.7 to 8.9). The corresponding incidences per 10000 exposure years were 9.7 and 7.8 events. The relative risk was increased in women who used subcutaneous implants $(1.4,0.6$ to 3.4$)$ but not in those who used the levonorgestrel intrauterine system $(0.6,0.4$ to 0.8$)$. Compared with users of combined oral contraceptives containing levonorgestrel, the adjusted relative risk of venous thrombosis in users of transdermal patches was 2.3 (1.0 to 5.2 ) and of the vaginal ring was 1.9 (1.3 to 2.7$)$.
Conclusion Women who use transdermal patches or vaginal rings for contraception have a 7.9 and 6.5 times increased risk of confirmed venous thrombosis compared with non-users of hormonal contraception of the same age, corresponding to 9.7 and 7.8 events per 10000 exposure years. The risk was slightly increased in women using subcutaneous implants but not in those using the levonorgestrel intrauterine system.

\section{Introduction}

Several studies have assessed the risk of venous thrombosis in women using oral contraceptives. ${ }^{1-10}$ However, none has assessed the risk in women using subcutaneous hormonal implants. A recent study reported a $48 \%$ higher risk of venous thrombosis in women using a vaginal ring compared with those using combined oral contraceptives containing levonorgestrel, ${ }^{11}$ and a few studies have reported the risk in women using a transdermal combined contraceptive patch, although the results were conflicting. ${ }^{12-16}$

Using a historical national registry based cohort study design, we assessed the absolute and relative risk of venous thrombosis in Danish women using non-oral hormonal contraception.

\section{Methods}

Information on the four national data sources that provided information for the study is provided in detail elsewhere. ${ }^{10}$ Briefly, from Statistics Denmark we obtained data on length of schooling, ongoing or finished education, vital status, and emigration of all Danish women aged 15-49 from 1 January 2001 to 31 December 2010. We censored women in cases of death or emigration.

Since 1977 the national registry of patients has collected discharge diagnoses from all public and private hospitals in Denmark (see appendix for a list of the relevant diagnoses and 
codes used in this study). To include only first ever events, we excluded women with any type of venous or arterial thrombotic event before the study period (1977-2000), those with cancer, those who had undergone bilateral oophorectomy or hysterectomy, and those who had been sterilised. From study follow-up we censored a woman's risk time during pregnancy, calculated from conception to three months after delivery, and women with a coagulation disorder from the first time such a diagnosis was recorded (appendix). The registry records only women admitted alive to hospital. Lethal events from venous thrombosis were captured in the national cause of death registry.

A diagnosis of venous thrombosis was confirmed through prescribed anticoagulation therapy recorded in the national registry of medicinal products for at least four weeks after the diagnosis. Since 1 January 1994, and validated from 1995, information on filled prescriptions, including hormonal contraception, collected by the national registry of medicinal products has been complete. From this database we obtained information that had been updated daily on redeemed prescriptions of hormonal contraception from 1995 to 2010. We categorised the products in use according to progestogen type, oestrogen dose, and route of being administered. Duration of use was estimated from the prescribed defined daily doses from the date of prescription until the end date of defined daily doses of the last redeemed prescription or date of a study event. When hormonal contraception was switched without pause, we calculated duration as the sum of use before switch and current use of the new preparation. If a pause lasted for more than four weeks, we reset the length of use. To account for use before study start (left censoring bias), we allocated continuous users of hormonal contraception to the relevant duration of use category on 1 January 2001 by assessing use before the study period back to 1995 .

Women who used the levonorgestrel intrauterine system were censored after three years and included again when a new prescription of a hormonal contraceptive product was recorded. This was done owing to missing information on removal of these devices.

Length of schooling and level of education were used as proxies for social class. Four strata were applied: elementary school education only, ongoing or completed high school education, high school and ongoing or ended middle length education, and high school and ongoing or ended long education. A fifth category included women without information on education, typically the youngest women.

We controlled for calendar year to deal with potential secular confounding of increasing adiposity by time.

Data on smoking were not available. Smoking is a weak risk factor for venous thrombosis in young women. However, we have no reason to believe in preferential prescribing of specific types of hormonal contraception among smokers. In Denmark the correlation between smoking and length of education is strong. Thus, controlling for years of schooling and length of education may have captured most confounding (if any) influenced by smoking.

As women treated for infertility with ovarian stimulation drugs (Anatomical Therapeutic Chemical code G03G) are anticipated to be at an increased risk of venous thrombosis, we censored these women during such treatment.

\section{Statistical analysis}

Using multiple Poisson regression we analysed data in five year age groups: $15-19,20-24$, and $45-49$ years. The non-oral contraceptive products included transdermal patches containing norelgestromin (the active metabolite of norgestimate) and ethinylestradiol, a vaginal ring with etonogestrel (third generation progestogen) and ethinylestradiol, subcutaneous implants containing etonogestrel only, and the levonorgestrel intrauterine system (hormone intrauterine device). Two reference oral contraceptives with levonorgestrel and norgestimate, respectively, were assessed for comparison.

We stratified the estimates into three categories according to length of contraceptive use ( $<1$ year, 1-4 years, $>4$ years). Absolute as well as relative risk estimates were calculated. The reference group for the relative risk estimates was non-users of all types of hormonal contraception (never users+former users). We calculated rate ratios for the different product types, with users of oral contraceptives containing 30-40 $\mu$ g oestrogen and levonorgestrel as reference. Tests for interaction with age and year were carried out.

Relative risk estimates were adjusted for age, calendar year, length of schooling and education, and eventually for length of contraceptive use. For all relative risk estimates and incidence rate ratios we calculated $95 \%$ confidence limits. We set the level of significance at $\mathrm{P}<0.05$.

\section{Results}

After exclusions and censoring, 1626158 non-pregnant women free of previous thrombotic diseases or cancer contributed 9 429128 woman years of observation. During this time 5287 diagnoses of first ever venous thrombosis events were recorded, corresponding to 8.1 per 10000 woman years. Current users of hormonal contraception contributed 3536946 woman years and of these, 325849 concerned non-oral products. Non-users of hormonal contraception contributed 5892182 woman years, with an overall incidence of confirmed venous thrombosis of 2.1 per 10000 woman years. The incidence of venous thrombosis increased by $42.9 \%$ during the 10 year study period, or by $4.3 \%$ per year (table $1 \Downarrow$ ). After adjustment for calendar year and use of hormonal contraception, the incidence increased by 6.3 -fold with increasing age and decreased by $51.2 \%$ with increasing length of education.

\section{Hormonal contraception and venous thrombosis}

Current use of combined oral contraceptives with 30-40 $\mu \mathrm{g}$ oestrogen and levonorgestrel increased the risk of confirmed venous thrombosis by 3.2 (2.7 to 3.8), corresponding to an incidence of 6.2 events per 10000 exposure years (table $2 \Downarrow$ ).

During 6178 woman years, six confirmed events of venous thrombosis were observed in association with transdermal combined contraceptive patches, corresponding to an incidence of 9.7 per 10000 exposure years. Compared with non-users of hormonal contraception, the adjusted relative risk was 7.9 (3.5 to 17.7) and compared with users of oral contraceptives containing levonorgestrel the rate ratio was 2.5 (1.1 to 5.6, tables 2 and $3 \Downarrow)$. After adjustment for length of use, the rate ratio was reduced to 2.3 (1.0 to 5.2). When compared with oral contraceptives containing the corresponding progestogen (norgestimate), the adjusted rate ratio was 2.2 (1.0 to 5.0).

During 50334 woman years, 39 confirmed venous thrombosis events were observed with the combined contraceptive vaginal ring, corresponding to an incidence of 7.8 per 10000 exposure years and an adjusted relative risk of 6.5 (4.7 to 8.9) compared with non-users of hormonal contraception. Compared with users of combined oral contraceptives with levonorgestrel, the rate 
ratio was 2.0 (1.4 to 2.9), which after adjustment for length of use was reduced to 1.9 (1.3 to 2.7 , tables 2 and 3 ).

During 29497 woman years, five confirmed venous thrombosis events were observed with progestogen only subcutaneous implants, corresponding to an incidence rate of 1.7 per 10000 exposure years and an adjusted relative risk of 1.4 (0.6 to 3.4, table 2) compared with non-users of hormonal contraception. Compared with users of combined oral contraceptives with levonorgestrel, the rate ratio was 0.4 ( 0.2 to 1.1 , table 3 ).

The adjusted relative risk of confirmed venous thrombosis with the levonorgestrel intrauterine system was 0.6 (0.4 to 0.8 , table 2). Compared with users of combined oral contraceptives with levonorgestrel, the rate ratio was 0.2 ( 0.1 to 0.3 , table 3$)$.

After stratification according to length of use, the relative risk of venous thrombosis in women using combined oral contraceptives was reduced with increasing length of use (table $4 \Downarrow)$. No reduction by time was seen in users of transdermal combined contraceptive patches or progestogen only contraception, and no consistent changes were seen for women who used the vaginal ring.

\section{Discussion}

Women who use combined hormonal transdermal patches or vaginal rings for contraception have a 7.9 or 6.5 times increased risk of venous thrombosis compared with non-users of hormonal contraception of the same age, corresponding to 9.7 and 7.8 events per 10000 exposure years. The risk was slightly increased in women using subcutaneous implants but not in those using the levonorgestrel intrauterine system.

An incidence rate of confirmed venous thrombosis in users of transdermal patches of 1 in 1000 exposure years was found in a recent American study, ${ }^{11}$ and a relative risk of 7.9 compared with non-users of hormonal contraception or twice the risk with use of the corresponding combined oral contraceptive containing norgestimate in several previous studies ${ }^{111^{14-16}}$ although not all ${ }^{12}{ }^{13}$ (table $5 \Downarrow$ ). These results are supported by pharmacokinetic studies showing $60 \%$ higher plasma levels of oestrogen in women who use transdermal patches compared with those using the corresponding combined oral contraceptive. ${ }^{17}$

With an incidence of 7.8 confirmed events per 10000 exposure years, the vaginal ring conferred a $90 \%$ higher risk of venous thrombosis than did combined oral contraceptives containing levonorgestrel, bringing the risk to the same level as that of combined oral contraceptives with third and fourth generation progestogens, and compatible with the Food and Drug Administration study. ${ }^{11}$ Supporting our and the FDA results is the three ${ }^{18}$ and five times ${ }^{19}$ increase in sex hormone binding globulin in users of vaginal ring contraception compared with users of combined oral contraceptives containing levonorgestrel, and the activated protein $\mathrm{C}$ sensitivity ratio 3.75 times higher than with oral contraceptives, ${ }^{19}$ both considered as surrogate markers for the risk of venous thrombosis.

The modest non-significant $40 \%$ increased relative risk of venous thrombosis in women using subcutaneous implants is not surprising, as other types of progestogen only contraception do not confer an increased risk, ${ }^{10}$ and it is less than half the risk found in users of combined oral contraceptives containing levonorgestrel.

The low risk of venous thrombosis in users of the levonorgestrel intrauterine system has been shown in previous studies. ${ }^{710} \mathrm{In}$ the present study this product actually significantly decreased the risk of venous thrombosis, suggesting that the influence of progestogen only contraception on risk of venous thrombosis may depend on dose.

The inconsistent changes with length of use for the non-oral products could be influenced by the low power in some of the length of use categories. Another possibility, however, is that the non-oral route influences the coagulation system and liver differentially compared with the oral route. Nor did the FDA report show any consistent change in risk with length of use of either the patch or the vaginal ring.

The clinical implications of the findings can be expressed in terms of the number of women who should change their hormonal contraceptive from the transdermal patch or the vaginal ring to combined oral contraceptives containing levonorgestrel to prevent one event of venous thrombosis in a year. If the incidence rate of venous thrombosis in women using combined oral contraceptives containing levonorgestrel is 6 per 10000 exposure years, the vaginal ring is 11 per 10 exposure years, and the transdermal patch is 14 per 10000 exposure years, then 2000 women using the vaginal ring and 1250 using the transdermal patch should shift to combined oral contraceptives with levonorgestrel to prevent one event of venous thrombosis in one year. A risk of 10 per 10000 woman years implies a risk of venous thrombosis of more than $1 \%$ over a 10 year user period. Therefore women are generally advised to use combined oral contraceptives with levonorgestrel or norgestimate, rather than to use transdermal patches or vaginal rings.

\section{Strengths and limitations of the study}

The inclusion of all Danish non-pregnant women over a decade ensures outstanding external validity. Information on use of hormonal contraception from a prescription database is the most reliable data on exposure available today for four reasons. Firstly, each pharmacy transfers data electronically by bar codes, eliminating typing errors. Secondly, the collection of these data in a central national database is done primarily for reimbursement purposes and therefore should not be biased by the pursuit of pharmacoepidemiological studies. Thirdly, the continued daily update of information on use eliminates recall bias, as we know from case-control studies, and the problems of continuous updating of data on exposure in cohort studies. Fourthly, we eliminated the problem of left censoring bias by assessing exposure to hormonal contraception over a six year period before our study started. And we were able to validate each venous thrombosis event by linking individual data on diagnosis to succeeding anticoagulation therapy.

We could not control for family disposition or for body mass index. Adiposity is a well documented risk factor for venous thrombosis. So far no study has shown any confounding influence from adiposity, as the rate ratio between hormonal contraception with different progestogens was not changed in studies adjusting for this information. ${ }^{6} 820$

\section{Conclusion}

Use of transdermal patches and vaginal rings conferred incidence rates of 9.7 and 7.8 confirmed venous thromboses per 10000 exposure years, and relative risks of 7.9 and 6.5 compared with non-use of hormonal contraception, respectively. A

subcutaneous progestogen only implant may increase the risk by $40 \%$, whereas the levonorgestrel intrauterine system did not confer any increased risk, but perhaps even protection.

This study was approved by the Danish Data Protection Agency (J No 2010-41-4778). 


\section{What is already known on this topic}

Combined oral contraceptives with levonorgestrel or norgestimate confer half the risk of venous thrombosis than oral contraceptives containing desogestrel, gestodene, or drospirenone

Progestogen only pills do not confer an increased risk of venous thrombosis

\section{What this study adds}

Women who use combined contraceptive transdermal patches are at an increased risk of venous thrombosis about eight times that of non-users of hormonal contraception, corresponding to 9.7 events per 10000 exposure years

Vaginal rings increased the risk of venous thrombosis 6.5 times compared with non-use of hormonal contraception, corresponding to 7.8 events per 10000 exposure years

The risk of venous thrombosis was not significantly increased with use of subcutaneous implants or the levonorgestrel intrauterine system compared with non-use of hormonal contraception

Contributors: $\varnothing\llcorner$ planned the study, supervised the analysis, interpreted the results, and wrote the manuscript. He is guarantor of the study. EL planned the study, interpreted the results, and revised the manuscript. LHN made the statistical analyses and interpreted the results. CWS prepared all data from the national registry of patients and national death registry. All authors discussed and approved the final manuscript. $\varnothing \mathrm{L}$ decided when and where to attempt publication.

Funding: The expenses were covered by the Gynaecological Clinic, Juliane Marie Centre, Rigshospitalet.

Competing interests: All authors have completed the ICMJE uniform disclosure form at www.icmje.org/coi_disclosure.pdf (available on request from the corresponding author) and declare: no support from any organisation for the submitted work. The primary investigator has within the last three years received honorariums for speeches in pharmacoepidemiological issues, including fees from Bayer Pharma Denmark, MSD Denmark, and Theramex, Monaco, and has been expert witness for plaintiff in a legal US case in 2011. EL has within the last three years participated in two congresses the expenses of which were covered by pharmaceutical companies. LHN and CWS declared no financial relationships with any organisations that might have an interest in the submitted work in the previous three years, and no other relationships or activities that could appear to have influenced the submitted work.

Ethical approval: Ethical approval is not requested for registry based studies in Denmark, and consent from participating patients is not required.

Data sharing: No additional data available.

1 World Health Organization Collaborative Study of Cardiovascular Disease and Steroid Hormone Contraception. Venous thromboembolic disease and combined oral contraceptives: results of international multicentre case-control study. Lancet 1995;346:1575-82.

2 Jick $\mathrm{H}$, Jick SS, Gurewich V, Myers MW, Vasilakis C. Risk of idiopathic cardiovascula death and nonfatal venous thromboembolism in women using oral contraceptives with differing progestagen components. Lancet 1995;346:1589-93.

3 Spitzer WO, Lewis MA, Heinemann LAJ, Thorogood M, MacRae KD. Third generation oral contraceptives and risk of venous thromboembolic disorders: an international case-control study. BMJ 1996;312:83-8.

4 Farmer RDT, Lawrenson RA, Thompson CR, Kennedy JG, Hambleton IR. Population-based study of risk of venous thromboembolism associated with various oral contraceptives. Lancet 1997;349:83-8.

5 Bloemenkamp KWM, Rosendaal FR, Büller HR, Helmerhorst FM, Colly LP, Vandenbroucke JP. Risk of venous thrombosis with use of current low-dose oral contraceptives is not explained by diagnostic suspicion and referral bias. Arch Intern Med 1999;159:65-70.
6 Vlieg AVH, Helmerhorst FM, Vandenbroucke JP, Doggen CJ, Rosendaal FR. The venous thrombotic risk of oral contraceptives, effects of oestrogen dose and progestagen type: results of the MEGA case-control study. BMJ 2009;339:b2921.

7 Lidegaard Ø, Løkkegaard E, Svendsen AL, Agger C. Hormonal contraception and risk of venous thromboembolism: national follow-up study. BMJ 2009;339:b2890.

8 Parkin L, Sharples K, Hernandez RK, Jick SS. Risk of venous thromboembolism in users of oral contraceptives containing drospirenone or levonorgestrel: nested case-control study based on UK General Practice Research Database. BMJ 2011;340:d2139.

9 Jick SS, Hernandez RK. Risk of non-fatal venous thromboembolism in women using oral contraceptives containing drospirenone compared with women using oral contraceptives containing levonorgestrel: case-control study using United States claims data. $B M\lrcorner$ 2011;340:d2151.

10 Lidegaard Ø, Nielsen LH, Skovlund CW, Skjeldestad FE, Løkkegaard E. Risk of venous thromboembolism from use of oral contraceptives containing different progestogens and oestrogen doses: Danish cohort study 2001-9. BMJ 2011;343:d6423.

11 Food and Drug Administration, Office of surveillance and epidemiology. Combined hormonal contraceptives (CHCs) and the risk of cardiovascular disease endpoints. FDA 2011. www.fda.gov/downloads/Drugs/DrugSafety/UCM277384.pdf.

12 Jick SS, Kaye JA, Russmann S, Jick H. Risk of nonfatal venous thromboembolism in women using a contraceptive transdermal patch and oral contraceptives containing norgestimate and $35 \mu \mathrm{g}$ of ethinyl estradiol. Contraception 2006;73:223-8.

13 Jick S, Kaye JA, Li L, Jick H. Further results on the risk of nonfatal venous thromboembolism in users of the contraceptive transdermal patch compared to users of oral contraceptives containing norgestimate and 35 microg of ethinyl estradiol. Contraception 2007;76:4-7.

14 Jick SS, Hagberg KW, Kaye JA. Ortho EVRA ${ }^{\oplus}$ and venous thromboembolism: an update. Contraception 2010;81:452-3.

15 Cole JA, Horman H, Doherty M, Walker AM. Venous thromboembolism, myocardial infarction, and stroke among transdermal contraceptive system users. Obstet Gynecol 2007;109:339-46.

16 Dore DD, Norman H, Loughlin J, Seeger JD. Extended case-control study results on thromboembolic outcomes among transdermal contraceptive users. Contraception 2010;81:408-13.

17 Van den Heuvel MW, van Bragt AJM, Alnabawy A, Kaptein MC. Comparison of ethinylestradiol pharmacokinetics in the transdermal patch, and an oral contraceptive. Contraception 2005;72:168-74.

18 Odlin V, Milsom I, Persson I, Victor A. Can changes in sex hormone binding globulin predict the risk of venous thromboembolism with combined oral contraceptive pills? Acta Obstet Gynecol Scand 2002;81:482-90.

19 Fleischer K, Vliet HAV, Rosendaal FR, Rosing J, Tchaikovski S, Helmerhorst FM. Effects of the contraceptive patch, the vaginal ring and an oral contraceptive on APC resistance and SHBG: a cross-over study. Thrombosis Res 2009;123:429-35.

20 Gronich N, Lavi I, Rennert G. Higher risk of venous thrombosis associated with drospirenone-containing oral contraceptives: a population-based cohort study. CMAJ 2011;183:E1319-25.

Accepted: 30 March 2012

\section{Cite this as: BMJ 2012;344:e2990}

This is an open-access article distributed under the terms of the Creative Commons Attribution Non-commercial License, which permits use, distribution, and reproduction in any medium, provided the original work is properly cited, the use is non commercial and is otherwise in compliance with the license. See: http://creativecommons.org/licenses/bync/2.0/ and http://creativecommons.org/licenses/by-nc/2.0/legalcode. 


\section{Tables}

Table 1/ Crude incidence rate and adjusted relative risk of confirmed venous thrombosis according to age, calendar year, and length of education

\begin{tabular}{|c|c|c|c|c|c|c|}
\hline \multirow[b]{2}{*}{ Variables } & \multirow[b]{2}{*}{ Woman years } & \multicolumn{2}{|c|}{ Venous thrombosis } & \multirow[b]{2}{*}{ Incidence per 10000 woman years } & \multirow[b]{2}{*}{ Adjusted relative risk ${ }^{*}(95 \% \mathrm{Cl})$} & \multirow[b]{2}{*}{$P$ value } \\
\hline & & All & Confirmed & & & \\
\hline \multicolumn{7}{|l|}{ Age: } \\
\hline $15-19$ & 1403925 & 365 & 251 & 1.79 & $0.16(0.13$ to 0.19$)$ & $<0.001$ \\
\hline $20-24$ & 1198098 & 479 & 326 & 2.72 & $0.19(0.16$ to 0.22$)$ & $<0.001$ \\
\hline $25-29$ & 1145729 & 594 & 387 & 3.38 & $0.30(0.27$ to 0.33$)$ & $<0.001$ \\
\hline 30-34 & 1299645 & 715 & 448 & 3.45 & $0.44(0.40$ to 0.48$)$ & $<0.001$ \\
\hline $35-39$ & 1509447 & 930 & 601 & 3.98 & $0.60(0.55$ to 0.66$)$ & $<0.001$ \\
\hline $40-44$ & 1510042 & 1105 & 705 & 4.67 & $0.82(0.75$ to 0.89$)$ & $<0.001$ \\
\hline $45-49$ & 1362242 & 1099 & 716 & 5.26 & 1.00 (reference) & - \\
\hline \multicolumn{7}{|l|}{ Year: } \\
\hline 2001 & 994095 & 444 & 315 & 3.17 & $0.70(0.61$ to 0.79$)$ & $<0.001$ \\
\hline 2002 & 979715 & 466 & 331 & 3.38 & 0.72 (0.64 to 0.82$)$ & $<0.001$ \\
\hline 2003 & 963470 & 438 & 304 & 3.16 & $0.68(0.60$ to 0.77$)$ & $<0.001$ \\
\hline 2004 & 953604 & 512 & 319 & 3.35 & $0.79(0.70$ to 0.89$)$ & $<0.001$ \\
\hline 2005 & 939935 & 525 & 362 & 3.85 & $0.81(0.72$ to 0.91$)$ & 0.0005 \\
\hline 2006 & 929975 & 537 & 363 & 3.90 & $0.84(0.74$ to 0.94$)$ & 0.0028 \\
\hline 2007 & 921713 & 615 & 391 & 4.24 & 0.97 (0.87 to 1.09$)$ & 0.6531 \\
\hline 2008 & 918349 & 538 & 347 & 3.78 & $0.87(0.77$ to 0.98$)$ & 0.0171 \\
\hline 2009 & 911825 & 599 & 365 & 4.00 & 0.98 (0.87 to 1.09 ) & 0.6597 \\
\hline 2010 & 916449 & 613 & 337 & 3.68 & 1.00 (reference) & - \\
\hline \multicolumn{7}{|l|}{ Education: } \\
\hline 1 (low) & 2164635 & 1819 & 1159 & 5.35 & 1.25 (1.11 to 1.42$)$ & 0.0004 \\
\hline 2 & 1026525 & 475 & 314 & 3.06 & 0.72 (0.62 to 0.83 ) & $<0.001$ \\
\hline 3 & 2236972 & 1456 & 974 & 4.35 & 0.83 (0.73 to 0.95 ) & 0.0087 \\
\hline 4 (high) & 1385214 & 602 & 382 & 2.76 & 0.61 (0.53 to 0.71 ) & $<0.001$ \\
\hline Not available & 2615782 & 935 & 605 & 2.31 & 1.00 (reference) & - \\
\hline
\end{tabular}

*Adjusted for age, calendar year, education, and use of hormonal contraception. 
Table 2/ Crude incidence rate and adjusted relative risk of venous thrombosis in current users of non-oral hormonal contraception and combined oral contraceptives $(\mathrm{COC})$ with non-users as reference

\begin{tabular}{|c|c|c|c|c|c|}
\hline Outcome, contraception type & Woman years & $\begin{array}{l}\text { No with venous } \\
\text { thrombosis }\end{array}$ & $\begin{array}{c}\text { Incidence per } 10000 \\
\text { exposure years }\end{array}$ & Adjusted relative risk $^{\star}(95 \% \mathrm{Cl})$ & $P$ value \\
\hline \multicolumn{6}{|l|}{ All venous thromboses: } \\
\hline Non-use & 5892182 & 2262 & 3.84 & 1.00 (reference) & - \\
\hline $\begin{array}{l}\mathrm{COC} \text { with levonorgestrel and } \\
30-40 \mu \mathrm{g} \text { oestrogen }\end{array}$ & 231675 & 201 & 8.68 & 2.37 (2.05 to 2.74$)$ & $<0.001$ \\
\hline COC with norgestimate & 298566 & 198 & 6.63 & 2.63 (2.27 to 3.05$)$ & $<0.001$ \\
\hline Patch & 6178 & 7 & 11.33 & 4.40 (2.09 to 9.24$)$ & $<0.001$ \\
\hline Vaginal ring & 50334 & 55 & 10.93 & 4.29 (3.27 to 5.62$)$ & $<0.001$ \\
\hline Implant & 29497 & 15 & 5.09 & 2.08 (1.25 to 3.46$)$ & 0.005 \\
\hline Levonorgestrel IUS & 239841 & 88 & 3.67 & 0.80 (0.65 to 0.99$)$ & 0.040 \\
\hline \multicolumn{6}{|l|}{ Confirmed events: } \\
\hline Non-use & 5892182 & 1209 & 2.05 & 1.00 (reference) & - \\
\hline $\begin{array}{l}\text { COC with levonorgestrel and } \\
30-40 \mu \mathrm{g} \text { oestrogen }\end{array}$ & 231675 & 144 & 6.22 & 3.21 (2.70 to 3.81$)$ & $<0.001$ \\
\hline COC with norgestimate & 298566 & 135 & 4.52 & 3.57 (2.98 to 4.27 ) & $<0.001$ \\
\hline Patch & 6178 & 6 & 9.71 & 7.90 (3.54 to 17.65$)$ & $<0.001$ \\
\hline Vaginal ring & 50334 & 39 & 7.75 & 6.48 (4.69 to 8.94$)$ & $<0.001$ \\
\hline Implant & 29497 & 5 & 1.70 & $1.40(0.58$ to 3.38$)$ & 0.450 \\
\hline Levonorgestrel IUS & 239841 & 33 & 1.38 & 0.57 (0.41 to 0.81$)$ & 0.002 \\
\hline
\end{tabular}

Patch=transdermal contraceptive patch (EVRA; Johnson \& Johnson, NJ, USA); implant=subcutaneous implant (Implanon; MSD; NJ, USA); vaginal ring=combined hormonal vaginal ring (NuvaRing; MSD, NJ, USA); levonorgestrel IUS=levonorgestrel intrauterine system (Mirena: Bayer Pharma, Berlin, Germany).

*Adjusted for age, calendar year, and education. 
Table 3| Rate ratio estimates of venous thrombosis between users of different types of non-oral hormonal contraception and users of combined oral contraceptives (COC) with levonorgestrel and 30-40 $\mu \mathrm{g}$ oestrogen (reference group)

\begin{tabular}{|c|c|c|c|c|}
\hline Outcome, contraception type & Woman years & $\begin{array}{l}\text { No with venous } \\
\text { thrombosis }\end{array}$ & Adjusted rate ratio $(95 \% \mathrm{Cl})^{*}$ & $P$ value \\
\hline \multicolumn{5}{|l|}{ All venous thrombosis: } \\
\hline $\begin{array}{l}\mathrm{COC} \text { with levonorgestrel and } 30-40 \mu \mathrm{g} \\
\text { oestrogen }\end{array}$ & 231675 & 201 & 1.00 (reference) & - \\
\hline $\mathrm{COC}$ with norgestimate & 298566 & 198 & $1.11(0.91$ to 1.35$)$ & 0.305 \\
\hline Patch & 6178 & 7 & 1.85 (0.87 to 3.94$)$ & 0.109 \\
\hline Vaginal ring & 50334 & 55 & 1.81 (1.34 to 2.44$)$ & 0.0001 \\
\hline Implant & 29497 & 15 & $0.88(0.52$ to 1.48$)$ & 0.623 \\
\hline Levonorgestrel IUS & 239841 & 88 & 0.34 (0.26 to 0.43$)$ & $<0.001$ \\
\hline \multicolumn{5}{|l|}{ Confirmed events: } \\
\hline $\begin{array}{l}\mathrm{COC} \text { with levonorgestrel and } 30-40 \mu \mathrm{g} \\
\text { oestrogen }\end{array}$ & 231675 & 144 & 1.00 (reference) & - \\
\hline $\mathrm{COC}$ with norgestimate & 298566 & 135 & $1.11(0.88$ to 1.41$)$ & 0.378 \\
\hline Patch & 6178 & 6 & 2.46 (1.09 to 5.58$)$ & 0.031 \\
\hline Vaginal ring & 50334 & 39 & 2.02 (1.41 to 2.89 ) & 0.0001 \\
\hline Implant & 29497 & 5 & $0.44(0.18$ to 1.07$)$ & 0.070 \\
\hline Levonorgestrel IUS & 239841 & 33 & $0.18(0.12$ to 0.26$)$ & $<0.001$ \\
\hline \multicolumn{5}{|l|}{ Confirmed events adjusted for length of use: } \\
\hline $\begin{array}{l}\mathrm{COC} \text { with levonorgestrel and } 30-40 \mu \mathrm{g} \\
\text { oestrogen }\end{array}$ & 231675 & 144 & 1.00 (reference) & - \\
\hline $\mathrm{COC}$ with norgestimate & 298566 & 135 & 1.09 (0.86 to 1.38$)$ & 0.465 \\
\hline Patch & 6178 & 6 & 2.31 (1.02 to 5.23$)$ & 0.045 \\
\hline Vaginal ring & 50334 & 39 & $1.90(1.33$ to 2.71$)$ & 0.001 \\
\hline Implant & 29497 & 5 & $0.43(0.18$ to 1.05$)$ & 0.064 \\
\hline Levonorgestrel IUS & 239841 & 33 & $0.18(0.12$ to 0.26$)$ & $<0.001$ \\
\hline
\end{tabular}

Patch=transdermal contraceptive patch (EVRA; Johnson \& Johnson, NJ, USA); implant=subcutaneous implant (Implanon; MSD; NJ, USA); vaginal ring=combined hormonal vaginal ring (NuvaRing; MSD, NJ, USA); levonorgestrel IUS=levonorgestrel intrauterine system (Mirena; Bayer Pharma, Berlin, Germany).

*Adjusted for age, calendar year, and education. 
Table 4| Relative risk of confirmed venous thrombosis in current users of different types of hormonal contraception according to length of use

\begin{tabular}{|c|c|c|c|c|}
\hline \multirow[b]{2}{*}{ Hormonal contraception } & \multirow{2}{*}{$\begin{array}{l}\text { No with confirmed } \\
\text { venous thrombosis }\end{array}$} & \multicolumn{3}{|c|}{ Adjusted relative risk $(95 \% \mathrm{Cl})^{*}$} \\
\hline & & $<1$ year & $1-4$ years & $>4$ years \\
\hline Non-use & 1209 & 1 (reference) & 1 (reference) & 1 (reference) \\
\hline $\begin{array}{l}\mathrm{COC} \text { with levonorgestrel and } \\
30-40 \mu \mathrm{g} \text { oestrogen }\end{array}$ & 144 & 4.25 (3.17 to 5.69$)$ & 3.07 (2.28 to 4.13$)$ & 2.71 (2.06 to 3.58$)$ \\
\hline COC with norgestimate & 135 & 4.97 (3.86 to 6.39 ) & 2.97 (2.19 to 4.03$)$ & 2.67 (1.82 to 3.92$)$ \\
\hline Patch & 6 & 6.89 (2.22 to 21.4$)$ & 11.9 (3.82 to 36.9$)$ & NA \\
\hline Vaginal ring & 39 & 8.36 (5.73 to 12.2$)$ & 3.83 (1.91 to 7.69$)$ & $5.37(1.73$ to 16.7$)$ \\
\hline Implant & 5 & $1.63(0.41$ to 6.52$)$ & $1.43(0.46$ to 4.45$)$ & NA \\
\hline Levonorgestrel IUS & 33 & 0.59 (0.34 to 1.05$)$ & 0.61 (0.39 to 0.94$)$ & NA \\
\hline
\end{tabular}

$\mathrm{COC}=$ combined oral contraceptive; patch=transdermal contraceptive patch (EVRA; Johnson \& Johnson, NJ, USA); implant=subcutaneous implant (Implanon; MSD, NJ, USA); vaginal ring=combined hormonal vaginal ring (NuvaRing; MSD; NJ, USA); levonorgestrel IUS=levonorgestrel intrauterine system (Mirena; Bayer Pharma, Berlin, Germany); NA=not available.

*Adjusted for age, calendar year, and education. 
Table 5| Incidence of venous thrombosis in users of transdermal contraceptive patch and corresponding combined oral contraceptive (COC) with norgestimate, and rate ratio of venous thrombosis in users of patch versus users of combined oral contraceptives with norgestimate

\begin{tabular}{|c|c|c|c|c|c|}
\hline \multirow[b]{2}{*}{ Study } & \multirow[b]{2}{*}{ Sampling period } & \multirow[b]{2}{*}{ No with venous thrombosis } & \multicolumn{2}{|c|}{ Incidence per 10000 exposure years } & \multirow[b]{2}{*}{ Rate ratio $(95 \% \mathrm{Cl})$} \\
\hline & & & Patch & COC with norgestimate & \\
\hline Jick $2006^{12}$ & $2002-05$ & 68 & 5.3 & 4.2 & $1.1(0.7$ to 1.8$)$ \\
\hline Jick $2007^{13}$ & $2002-06$ & 56 & NA & NA & $1.1(0.6$ to 2.1$)$ \\
\hline Jick $2010^{14}$ & $2002-07$ & 38 & NA & NA & $2.4(1.2$ to 5.0$)$ \\
\hline Cole $2007^{15}$ & $2002-04$ & 57 & 4.1 & 1.8 & 2.2 (1.3 to 3.8$)$ \\
\hline Dore $2010^{16}$ & $2002-06$ & 201 & NA & NA & $2.0(1.2$ to 3.3$)$ \\
\hline FDA $2011^{11}$ & $2001-07$ & 625 & 9.6 & $6.6^{*}$ & $1.3^{*}(0.9$ to 1.7$)$ \\
\hline Lidegaard $2011^{10}$ & $2001-10$ & 3434 & 9.7 & 4.5 & $2.2(1.0$ to 5.0$)$ \\
\hline
\end{tabular}

$\mathrm{NA}=$ not available; FDA=Food and Drug Administration.

${ }^{*}$ Reference group was users of combined oral contraceptives with levonorgestrel and 30-40 $\mu \mathrm{g}$ oestrogen. 